\title{
Cosmogenic Effects on Cu Isotopes in IVB Iron Meteorites
}

Heng Chen $^{\mathrm{a} *}$, Frédéric Moynier ${ }^{\mathrm{a}, \mathrm{b}, \mathrm{c}}$, Munir Humayun ${ }^{\mathrm{d}}$, Matthew C. Bishop ${ }^{\mathrm{a}}$, Jeffrey T. Williams $^{\mathrm{d}, \mathrm{e}}$

${ }^{a}$ Department of Earth and Planetary Sciences and McDonnell Center for the Space Sciences, Washington University in St. Louis, One Brookings Drive, St. Louis, MO 63130, USA

${ }^{\text {b }}$ Institut de Physique du Globe de Paris, Université Paris Diderot, Sorbonne Paris Cité, CNRS, 1 Rue Jussieu, Paris 75238, France

${ }^{\mathrm{c}}$ Institut Universitaire de France, Paris, 75005, France

${ }^{\mathrm{d}}$ National High Magnetic Field Laboratory and Department of Earth, Ocean \& Atmospheric Science, Florida State University, Tallahassee, FL 32310, USA.

${ }^{\text {e }}$ Presently at: Department of Earth and Planetary Sciences, University of New Mexico, Albuquerque, NM 87131, USA.

*Corresponding author

Email address: chenheng@levee.wustl.edu

Tel: +1 3146609748 


\section{Abstract}

2 We measured $\mathrm{Cu}$ isotope compositions of 12 out of the 14 known IVB iron meteorites. Our results show

3 that IVB iron meteorites display a very large range of $\delta^{65} \mathrm{Cu}$ values $\left(-5.84 \%<\delta^{65} \mathrm{Cu}<-0.24 \%\right.$; defined

4 as per mil deviation of the ${ }^{65} \mathrm{Cu} /{ }^{63} \mathrm{Cu}$ ratio from the NIST-976 standard). These $\mathrm{Cu}$ isotopic data display

5 clear correlations with $\mathrm{W}, \mathrm{Pt}$, and Os isotope ratios, which are very sensitive to secondary neutron capture

6 due to galactic cosmic ray (GCR) irradiation. This demonstrates that $\delta^{65} \mathrm{Cu}$ in IVB irons is majorly

7 modified by neutron capture by the reaction ${ }^{62} \mathrm{Ni}(\mathrm{n}, \gamma){ }^{63} \mathrm{Ni}$ followed by beta decay to ${ }^{63} \mathrm{Cu}$. Using

8 correlations with $\mathrm{Pt}$ and Os neutron dosimeters, we calculated a pre-exposure $\delta^{65} \mathrm{Cu}$ of $-0.3 \pm 0.8 \%$ o $(95 \%$

9 conf.) of IVB irons that agrees well with the $\mathrm{Cu}$ isotopic compositions of other iron meteorite groups and

10 falls within the range of chondrites. This shows that the volatile depletion of the IVB parent body is not

11 due to evaporation that should have enriched IVB irons in the heavy $\mathrm{Cu}$ isotopes.

13 Keywords: IVB iron meteorites; Copper isotopes; Cosmic ray exposure; Neutron capture 


\section{Introduction}

Copper is a moderately volatile element $\left(\mathrm{T}_{\mathrm{c}}=1037 \mathrm{~K}\right.$; Lodders, 2003), and follows a chalcophile /siderophile behavior during planetary differentiation processes (Righter et al., 2010). It has two stable isotopes: ${ }^{63} \mathrm{Cu}(69.17 \%)$ and ${ }^{65} \mathrm{Cu}(30.83 \%)$ and even though few data have been published on the natural fractionation of $\mathrm{Cu}$ isotopes in terrestrial rocks, it seems that $\mathrm{Cu}$ has a very limited isotopic fractionation during igneous processes (Savage et al., 2015). In a survey of the $\mathrm{Cu}$ isotope compositions of iron meteorites, Bishop et al. (2012) observed that IVB irons $(\mathrm{n}=3)$ had distinctly negative $\delta^{65} \mathrm{Cu}(\sim-2 \%$; $\delta^{65} \mathrm{Cu}$ defined as the per mille deviation of a sample's ${ }^{65} \mathrm{Cu} /{ }^{63} \mathrm{Cu}$ compositional ratio from that of the NIST-976 standard), which deviates from the values of chondrites $\left(-1.51 \%<\delta^{65} \mathrm{Cu}<0.07 \%\right.$; Luck et al., 2003; Barrat et al., 2012) and other iron meteorite groups $\left(-1.83 \%<\delta^{65} \mathrm{Cu}<0.99 \%\right.$; Luck et al., 2005; Bishop et al., 2012). Magmatic iron meteorites are believed to represent samples of the metallic cores of small planetary bodies (Scott, 1972). Among iron meteorite groups, the IVB group is the most volatile depleted with low concentrations of moderately volatile elements (e.g. $\mathrm{Ga}, \mathrm{Ge}$, and $\mathrm{Cu}$ ) coupled with high concentrations of $\mathrm{Ni}(16-18$ wt.\%) and other refractory elements (e.g. Ir, Re; Campbell and Humayun, 2005; Walker et al., 2008). Bishop et al. (2012) proposed a precursor with a non-chondritic $\mathrm{Cu}$ isotopic composition for the IVB parent body to explain their uniquely light $\mathrm{Cu}$ isotopic composition. This explanation contradicts the prediction that angrites may represent the silicate portion of the IVB parent body (Campbell and Humayun, 2005).

The ${ }^{182} \mathrm{Hf}-{ }^{182} \mathrm{~W}$ system $\left(\mathrm{t}_{1 / 2}=8.9 \pm 0.1 \mathrm{Myr}\right.$; Vockenhuber et al., 2004) has proven to be a very important short-lived chronometer for dating metal-silicate differentiation events that occurred in the first 60 Myrs of the Solar System's history (Kleine et al., 2002; Schoenberg et al., 2002; Yin et al., 2002; Kleine et al., 2004; Jacobsen, 2005; Moynier et al., 2010a). However, some of the iron meteorites were found to have lower $\varepsilon^{182} \mathrm{~W}$ values (relative deviation of the ratio of ${ }^{182} \mathrm{~W}$ to a stable $\mathrm{W}$ isotope from a terrestrial standard in parts per $10^{4}$; Kleine et al., 2005; Lee, 2005; Markowski et al., 2006a; Schersten et al., 2006; Qin et al., 2008) than the initial $\varepsilon^{182} \mathrm{~W}$ value $(-3.51 \pm 0.10)$ of the calcium-aluminum-rich 
inclusions (CAIs; Burkhardt et al., 2012). The abnormally low $\varepsilon^{182} \mathrm{~W}$ values in these iron meteorites reflect superimposed neutron capture effects that result from long-duration exposure to galactic cosmic rays (GCR; Masarik, 1997; Leya et al., 2003; Markowski et al., 2006a, 2006b; Qin et al., 2008). When

42

43

44 subjected to intense GCR irradiation, particles with energies of several MeV or more may induce nuclear reactions, including spallation and secondary neutron capture reactions in meteorites. Most iron meteorites have cosmic-ray exposure ages of several hundred Myrs, much larger than stony meteorites (Voshage and Feldmann, 1979; Voshage, 1984). Recent studies have found that neutron capture effects also modify the isotopic compositions of some other siderophile elements (e.g., Os, Ir, Pt, Rh, Pd) in iron meteorites (Walker, 2012; Wittig et al., 2013; Kruijer et al., 2013; Kruijer et al., 2014; Mayer et al., 2015); for example, neutron capture reactions create detectable ${ }^{192} \mathrm{Pt}$ and ${ }^{190} \mathrm{Os}$ excesses coupled with ${ }^{189} \mathrm{Os}$ deficits (Walker, 2012; Wittig et al., 2013; Kruijer et al., 2013; Kruijer et al., 2014). These siderophile elements have comparable cross sections for secondary neutrons to $\mathrm{W}$, so cosmogenic Pt and Os isotopic anomalies have been applied as in situ neutron dosimeters for ${ }^{182} \mathrm{~W}$ correction (Kruijer et al., 2013; Wittig et al., 2013; Kruijer et al., 2014).

Among all the Ni isotopes, ${ }^{62} \mathrm{Ni}$ has the largest thermal neutron capture cross section (14.5 barns) and epithermal resonance integral (6.6 barns; Mughabghab, 2003), so a potential neutron capture reaction, ${ }^{62} \mathrm{Ni}(\mathrm{n}, \gamma){ }^{63} \mathrm{Ni}\left(\beta^{-}\right){ }^{63} \mathrm{Cu}$ might have produced excessive ${ }^{63} \mathrm{Cu}$ in these IVB irons due to extremely high $\mathrm{Ni} / \mathrm{Cu}$ ratio $\left(\sim 1.1 \times 10^{5} ; 3\right.$ orders of magnitude higher than the ratios in CI chondrites), leading to some very low $\delta^{65} \mathrm{Cu}$ values as observed by Bishop et al. (2012). Thus, studying $\mathrm{Cu}$ isotopic variations among IVB irons is essential to constrain the magnitude of cosmogenic neutron capture to $\mathrm{Cu}$ isotopes.

In the present study, we measured $\mathrm{Cu}$ isotope compositions of 12 IVB iron meteorites from the same samples analyzed for W, Os, and Pt isotope compositions (Wittig et al., 2013) and found a good correlation between $\mathrm{Cu}$ isotopes and recently published $\mathrm{W}$, Os, and Pt data, which are known to be modified by GCR neutron capture processes. We suggest that the $\mathrm{Cu}$ isotopic compositions of IVB meteorites are controlled by neutron capture effects on ${ }^{62} \mathrm{Ni}$. We further correct for the neutron capture 
effect on $\mathrm{Cu}$ isotopes by coupling our data with previously measured $\mathrm{Pt}$ and Os isotopes to obtain a pre-

65 irradiation value of $\delta^{65} \mathrm{Cu}$ for IVB irons.

66

\section{2. Samples}

In order to test our assumption that $\mathrm{Cu}$ isotopes of IVB iron meteorites have been modified by GCR,

69 the $\mathrm{Cu}$ isotopic compositions of 12 of the 14 known IVB iron meteorites were measured by high-

70 precision Multiple-Collector Inductively Coupled Plasma Mass Spectrometry (MC-ICP-MS). Since

71 neutron capture effects vary with depth within a meteorite body, these samples were taken within $2 \mathrm{~mm}$

72 from the samples for which $\mathrm{Pd}$, Os, Pt, and W isotopic compositions have been reported by Wittig et al.

73 (2013) and Mayer et al. (2015). This sample set, based on previously reported cosmic ray exposure age

74 data (Voshage and Feldmann, 1979) and W isotope compositions (Kleine et al., 2005; Markowski et al.,

75 2006a; Qin et al., 2008; Wittig et al., 2013; Kruijer et al., 2013, 2014) is likely to cover a wide range in

76 degrees of GCR irradiation.

77 In addition, we also report $\mathrm{Cu}$ isotopic compositions of 7 USGS geostandards (dunite DTS-1,

78 peridotite PCC-1, andesite AGV-2, and basalts BCR-1, BCR-2, BIR-1, and BHVO-2) in order to test the

79 reproducibility of our analytical technique, as well as to provide more data on the $\mathrm{Cu}$ isotopic 80 composition of the Earth.

81

\section{3. Analytical methods}

83 Based on estimated $\mathrm{Cu}$ concentrations, $0.5-1 \mathrm{~g}$ of metal was cut and polished for isotopic analysis.

84 Metallic chips were first cleaned in diluted $\mathrm{HCl}$, and then rinsed with deionized water in an ultrasonic

85 bath to get rid of surface contamination. Cleaned samples were digested in aqua regia in PTFE containers

86 under hot lamps for $>48$ hours until complete dissolution was observed. Purification of $\mathrm{Cu}$ was achieved 
87 by anion exchange chromatography following the procedure described in Marechal et al. (1999) and Bishop et al. (2012). The samples were loaded in $1 \mathrm{ml}$ of $7 \mathrm{~mol} / \mathrm{L} \mathrm{HCl}$ on $1.6 \mathrm{~mL}$ of anion-exchange resin (AGMP1). Matrix elements were eluted by $7 \mathrm{ml}$ of $7 \mathrm{~mol} / \mathrm{L} \mathrm{HCl}$ and $\mathrm{Cu}$ was extracted by further addition of $19 \mathrm{ml}$ of $7 \mathrm{~mol} / \mathrm{L} \mathrm{HCl}$. This process was repeated twice to further purify $\mathrm{Cu}$.

Copper isotopic compositions were measured on a Thermo-Finnigan Neptune Plus ${ }^{\mathrm{TM}}$ MC-ICP-MS at Washington University in St. Louis following the procedure described in Weinstein et al. (2011) and Bishop et al. (2012). Samples were introduced into the mass spectrometer in $0.1 \mathrm{~mol} / \mathrm{L} \mathrm{HNO}_{3}$ via a CPITM PFA nebulizer attached to a glass spray chamber. All samples and standards were adjusted to the same concentration $(150 \pm 10 \mathrm{ppm})$ for mass spectrometer analysis. Isotope intensities were collected simultaneously in static mode using a multiple faraday collector array. Twenty-five integrations of $5 \mathrm{~s}$ duration were acquired during one sample measurement with an associated internal error on the ${ }^{65} \mathrm{Cu} /{ }^{63} \mathrm{Cu}$ of about $2-4 \times 10^{-6}$.

Isotope measurements were performed using standard-sample bracketing to correct for any instrumental drift over time. Copper isotopic ratio is expressed in $\delta$ per mil units with respect to the standard NIST-976 as:

$$
\delta^{65} \mathrm{Cu}=\left[\left({ }^{65} \mathrm{Cu} /{ }^{63} \mathrm{Cu}_{\text {sample }}\right) /\left({ }^{65} \mathrm{Cu} /{ }^{63} \mathrm{Cu}_{\text {NIST- }-976}\right)-1\right] \times 1000
$$

Each sample was measured at least twice and the average is reported. The blank of the total procedure (dissolution and chemical purification) is $<5 \mathrm{ng}$, which is negligible compared with the total amount of $\mathrm{Cu}$ present in the samples ( > $300 \mathrm{ng}$ ). The external reproducibility ( 2 s.d.) of the $\delta^{65} \mathrm{Cu}$ is $0.10 \%$ for iron meteorites (see Bishop et al., 2012).

The $\mathrm{Ni}$ and $\mathrm{Cu}$ concentrations were determined by laser ablation ICP-MS at Florida State University following the method described in Humayun (2012) and Williams and Humayun (2013).

\section{Results}


111 The $\mathrm{Cu}$ isotopic compositions of well-characterized USGS standards (DTS-1, PCC-1, AGV-2, BCR-1,

112 BCR-2, BIR-1, and BHVO-2) are listed in Table 1 together with some previously reported analyses. The

113 good agreement between our data and literature values demonstrates the robustness of the methods and of

114 our analyses. These igneous geostandard samples have very similar $\mathrm{Cu}$ isotopic compositions within the

115 errors, showing a typical terrestrial composition, which scatters around 0 \%o (Albarède, 2004; Ben

116 Othman et al., 2006).

117 The $\mathrm{Ni}$ and $\mathrm{Cu}$ concentration and $\mathrm{Cu}$ isotopic composition for each of the $12 \mathrm{IVB}$ iron meteorites are

118 listed in Table 2, together with corresponding W, Pt, and Os isotope data from Wittig et al. (2013). The 119 IVB irons display relatively small variations in $\mathrm{Ni}(15.68-17.87 \mathrm{wt} . \%)$ and $\mathrm{Cu}(1.26-1.79 \mathrm{ppm})$ 120 contents, with $\mathrm{Ni} / \mathrm{Cu}$ ratio ranging from $9.9-12.9 \times 10^{4}, \sim \times 10^{2}$ higher than in IVA iron meteorites.

121 Although a small nucleosynthetic anomaly in $\varepsilon^{184} \mathrm{~W}$ has been confirmed in IVB irons, the nucleosynthetic 122 anomalies are negligible on $\varepsilon^{182} \mathrm{~W}$ (Qin et al., 2008; Wittig et al., 2013; Kruijer et al., 2013). The $\delta^{65} \mathrm{Cu}$ 123 values of IVB irons are widely scattered between -0.24 and -5.84 \%o. Compared with chondrites and other 124 groups of iron meteorites, IVB irons have a much larger $\delta^{65} \mathrm{Cu}$ span, and most of them display significant 125 enrichment in ${ }^{63} \mathrm{Cu}$ isotopes (or depletion in ${ }^{65} \mathrm{Cu}$ ). Of the IVB iron meteorites, Weaver Mountains is the 126 least modified by GCR-induced ${ }^{182} \mathrm{~W}$ burn-out and has the highest $\delta^{65} \mathrm{Cu}$ value, falling within the range of 127 chondrites and other iron meteorites. In contrast, Tlacotepec, one of the most cosmic ray-irradiated 128 samples, has the lowest $\delta^{65} \mathrm{Cu}$ measured in this study, of $-5.84 \%$, which deviates the most from the 129 average composition of chondrites.

\section{Discussion}

\subsection{Mechanisms of $\mathrm{Cu}$ isotopic fractionation}


relatively homogeneous $(\leq 1 \%)$. The IVB iron meteorites show a much larger range of variability $(\sim 6 \%)$, and the IVB is the only group that does not fall within the chondritic range. It was suggested that massdependent processes such as evaporation-condensation and fractional crystallization could account for the

138 small variations within the group (Bishop. et al., 2012), but it is unclear that such processes could 139 fractionate $\mathrm{Cu}$ isotopes to the magnitude observed in the IVB group. In the following sections we will 140 consider the different possible mechanisms of $\mathrm{Cu}$ isotopic fractionation.

\subsubsection{Copper isotope fractionation during low-temperature alteration processes}

142 Low-temperature alteration and biological processes could generate significant $\mathrm{Cu}$ isotopic fractionations

143 (Albarède, 2004). For example, iron and copper minerals from supergene profile of the Bayugo porphyry

144 copper-gold deposit yielded $\delta^{65} \mathrm{Cu}$ values between -3.4 and $+6.9 \%$ (Braxton and Mathur, 2011).

145 However, any low-temperature fractionation process (e.g. aqueous alteration) that occurred on the IVB

146 parent body prior to the core formation would have been homogenized in the melt from which all IVB

147 irons crystallized, and would not be expected to create large isotopic variations among individual IVB

148 irons. Previous studies on Re-Os isotopic systematics (Walker et al., 2008) and siderophile element 149 concentrations in IVB irons (Campbell and Humayun, 2005; Walker et al., 2008) both confirmed that 150 their parent body remained a chemically closed system after crystallization. In addition, our samples were 151 specifically selected from polished interior slices, free from fusion crust or from oxidation products. Each 152 sample was polished to remove sawn surfaces. Therefore, $\mathrm{Cu}$ isotopic variations in these samples should 153 not be the result of alteration that occurred after crystallization either.

\section{$154 \quad 5.1 .2$ Copper isotope fractionation during evaporation processes}

155 Copper is a moderately volatile element, with a $50 \%$ condensation temperature $\left(\mathrm{T}_{\mathrm{c}}\right)$ of $1037 \mathrm{~K}$ (Lodders, 156 2003). Previous studies have observed that $\mathrm{Cu}$ isotopes are substantially fractionated during evaporation157 condensation processes (Herzog et al., 2009; Moynier et al., 2010b). The IVB group contains the lowest concentrations of moderately volatile elements among all iron meteorite groups, which either reflects high 
(Rasmussen et al., 1984; Campbell and Humayun, 2005). During the process of evaporation, light

161 isotopes of an element are preferentially lost into vapor, leaving the residual phase enriched in heavier

162 isotopes (Humayun and Clayton, 1995; Humayun and Cassen, 2000). This has been observed in shock-

163 melted rocks (Albarede et al., 2004), especially in the tektites (hypervelocity impact glasses) that are

164 among the terrestrial samples with the heaviest $\mathrm{Cu}$ isotopic composition $\left(\delta^{65} \mathrm{Cu}\right.$ up to $6.99 \%$; Moynier et

165 al., 2010b), although no such fractionation of potassium $\left(T_{c}=1006 \mathrm{~K}\right)$ isotopes is observed in tektites or

166 in impact melts (Humayun and Clayton, 1995; Humayun and Koeberl, 2004). Since IVB irons are

167 significantly depleted in heavier $\mathrm{Cu}$ isotopes, which is opposite to what is expected from an evaporation

168 process (Fig. 1), our new data agree with the conclusions by Bishop et al. (2012) that partial vaporization

169 did not modify $\mathrm{Cu}$ isotopes in IVB irons, and that the severe depletions of $\mathrm{Cu}$ and other moderately

170 volatile elements in IVB irons must have been induced by other mechanisms.

\section{$171 \quad 5.1 .3$ Copper isotope fractionation during igneous processes}

172 Although the volatile history and accretion processes of IVB parent body are still under debate (Campbell 173 and Humayun, 2005; Walker et al., 2008; Yang et al., 2010; Williams and Humayun, 2013), the variations 174 of chemical compositions within the IVB group can be successfully modeled as the result of simple 175 crystallization of the metallic liquid in a closed system (Walker et al., 2008). Previous studies have 176 suggested that isotopic fractionations observed in iron meteorites might have been created during the 177 partitioning of $\mathrm{Cu}$ between metal and silicates (Luck et al., 2003; Moynier et al., 2007). Metal-silicate 178 fractionation could give rise to a small isotope shift of the parental IVB metallic liquid relative to any 179 plausible chondritic starting composition, and Savage et al. (2015) showed that this was < 0.1\%. The 180 magmatic differentiation is unlikely to account for the $\mathrm{Cu}$ isotopic variations observed in IVB irons for 181 the following reasons:

182 First, no such large span of $\delta^{65} \mathrm{Cu}$ has been found in any other group of magmatic iron meteorites, which 183 exhibits similar or even larger ranges of fractional crystallization (Goldstein et al., 2009). Current studies 184 have shown that most of the iron groups have relatively homogeneous $\mathrm{Cu}$ isotopic composition $\left(\delta^{65} \mathrm{Cu}\right.$ 
variation $<1 \%$ ) within each group (Bishop et al., 2012). Among all the major iron meteorite systems, IVB group has the simplest chemical evolution that resulted from crystallization of a metallic liquid (Walker et al., 2008), so it is unlikely that magmatic differentiation could induce $\delta^{65} \mathrm{Cu}$ fractionation up to $5.6 \%$ in IVB irons.

Second, $\delta^{65} \mathrm{Cu}$ variation is independent of magmatic evolution among IVB irons. Rhenium ( $\left.\mathrm{Re}\right)$ is a highly compatible element, whose concentration decreases with increasing degree of fractional crystallization, and thus it has been applied as an indicator of magmatic differentiation in iron meteorites (Walker et al., 2008). During fractional crystallization, $\mathrm{Cu}$ isotope fractionation between solid metal and the residual liquid may give rise to $\mathrm{Cu}$ isotope differences that are a function of the extent of fractional crystallization. Since $\mathrm{Cu}$ isotopes do not correlate with $\mathrm{Re}$ abundances (Fig. $2, \mathrm{R}^{2}=0.16$ ), this effect is not important in controlling the $\mathrm{Cu}$ isotope composition of individual IVB irons.

Finally, the published $\mathrm{Cu}$ isotopic data of igneous rocks showed that $\mathrm{Cu}$ isotopic fractionation induced by magmatic differentiation is rather limited (Savage et al. 2015). The $\delta^{65} \mathrm{Cu}$ values of igneous standards derived from different geological settings (see table 1) and unaltered igneous rocks acquired by previous studies are narrowly distributed between -0.1 and $0.3 \%$ (Albarède, 2004; Ben Othman et al., 2006; Li et al., 2009; Savage et al., 2015). Although these igneous rocks went through different degrees of fractional crystallization, the variations of $\mathrm{Cu}$ isotopes are much smaller than what was measured in IVB irons (5.6\%). Therefore we conclude that it is unlikely that high-temperature magmatic processes could induce

$203 \delta^{65} \mathrm{Cu}$ fractionation up to the scale of $5.6 \%$ as observed in IVB irons.

\subsubsection{Nucleosynthetic Effects and short-lived radionuclides in Iron Meteorites}

205 Copper has only two stable isotopes, and thus it is impossible to differentiate between mass-dependent 206 and mass-independent fractionation (e.g. nucleosynthetic effect and radioactive decay). However, from 207 the discussion above, we exclude mass-dependent fractionation processes such as low-temperature alteration, high-temperature volatilization, and magmatic differentiation as the major processes that fractionate $\mathrm{Cu}$ isotopes in IVB irons. For some metal elements, mass-independent effects have been 
211 2002; Burkhardt et al., 2011), Ru (Chen et al. 2010; Fischer-Gödde et al., 2015) and Pd (Mayer et al.,

212 2015). These isotopic anomalies most likely result from heterogeneous distribution of isotopically diverse

213 presolar dust in the Solar System at the time when iron meteorite parent bodies formed (Trinquier et al.,

214 2007; Burkhardt et al., 2011). However, the magnitudes of nucleosynthetic effects in these elements are

215 rather small $\left(<0.1 \% \mathrm{amu}^{-1}\right)$. For example, the total ranges of $\varepsilon^{60} \mathrm{Ni}_{58 / 61}, \varepsilon^{62} \mathrm{Ni}_{58 / 61}$, and $\varepsilon^{64} \mathrm{Ni}_{58 / 61}$ in iron

216 meteorites (including IC, IIAB, IIIAB, IVA, IVB) are only $0.14,0.36$, and 0.69 per ten thousand,

217 respectively (Steele et al., 2011). In addition, any nucleosynthetic anomalies should be present in all IVB

218 irons equally after the melting and differentiation of parent body. Therefore, even if $\mathrm{Cu}$ isotopes were not

219 well mixed in the Solar System by the time of IVB parent body formation, the magnitude of

220 nucleosynthetic effect on $\delta^{65} \mathrm{Cu}$ is very unlikely to be more than $0.1 \%$, which is negligible compared to

221 the range of $\mathrm{Cu}$ isotopes in IVB irons.

222 The radioactive decay of some short-lived radionuclides, which were synthesized in stars or by irradiation

223 in the early Solar System, could also create isotopic anomalies in meteorites and their components (e.g.

224 Lee et al., 1976; Lugmair and Shukolyukov, 1998). The decay of the short-lived nuclide ${ }^{63}$ Ni produces

$225{ }^{63} \mathrm{Cu}$ by beta decay. The presence of ${ }^{63} \mathrm{Ni}$ at the time of fractional crystallization in the IVB iron parent

226 body could potentially lead to variation of $\delta^{65} \mathrm{Cu}$ among individual irons, which is due to different

227 parent/daughter $\left({ }^{63} \mathrm{Ni} /{ }^{63} \mathrm{Cu}\right)$ ratios created by chemical differentiation.

228 After melting and mixing inside the IVB parent body, the short-lived ${ }^{63} \mathrm{Ni}$ is expected to be 229 homogeneously distributed throughout the melt from which all IVB irons crystallized. The radiogenic 230 ingrowth model is shown in Figure 3, assuming a ${ }^{63} \mathrm{Ni} /{ }^{60} \mathrm{Ni}$ of $1 \times 10^{-5}$ at the birth of the Solar System and a $231 \delta^{65} \mathrm{Cu}$ of 0 at the time of fractional crystallization. All the variations of $\delta^{65} \mathrm{Cu}$ and $\mathrm{Ni} / \mathrm{Cu}$ reflect the growth 232 with time of radiogenic ${ }^{63} \mathrm{Cu}$ excesses due to decay of short lived ${ }^{63} \mathrm{Ni}$. The four isochron lines (with a 233 solidification age of 500, 750, 1000, 1250, and 2000 years respectively) display linearly negative 234 correlation between $\delta^{65} \mathrm{Cu}$ and the $\mathrm{Ni} / \mathrm{Cu}$ ratio. Had the IVB irons crystallized very quickly after the birth 235 of the Solar System (e.g. $<1000$ years after the synthesis of ${ }^{63} \mathrm{Ni}$ nuclide), resolvable $\delta^{65} \mathrm{Cu}$ differences 
could be detected between individual IVB irons due to different $\mathrm{Ni} / \mathrm{Cu}$ ratios. However, as the half-life of

${ }^{63} \mathrm{Ni}$ is only 100.1 years, which is thousand times shorter than the shortest known isotope chronometers

238 found in meteorites, e.g., ${ }^{41} \mathrm{Ca}\left(1.02 \times 10^{5}\right.$ years $),{ }^{26} \mathrm{Al}\left(7.17 \times 10^{5}\right.$ years $)$, etc., it is too short-lived to have 239 been present in the early Solar System. Even though we used a higher initial ${ }^{63} \mathrm{Ni} /{ }^{60} \mathrm{Ni}$ ratio $\left(1 \times 10^{-5}\right)$ than 240 the estimation $\left(\sim 5 \times 10^{-6}\right)$ by Luck et al. (2003), as the model predicted, no resolvable $\delta^{65} \mathrm{Cu}$ fractionation 241 due to the radioactive decay of ${ }^{63} \mathrm{Ni}$ would exist if fractional crystallization occurred 2000 years after the 242 production of ${ }^{63} \mathrm{Ni}$ nuclides. The IVB irons formed about $~ 1 \mathrm{Ma}$ after CAIs (Wittig et al., 2013; Kruijer et 243 al., 2013), so it is inconceivable that nucleosynthetic ${ }^{63} \mathrm{Ni}$ could have been present in the parental liquid 244 from which IVBs formed.

245 If ${ }^{63} \mathrm{Ni}$ was present at the time of crystallization of the IVB iron meteorites, a linear anti-correlation 246 between the $\mathrm{Ni} / \mathrm{Cu}$ ratio of individual irons and their $\delta^{65} \mathrm{Cu}$ would be expected. However, there is no clear 247 correlation between $\delta^{65} \mathrm{Cu}$ and $\mathrm{Ni} / \mathrm{Cu}$ ratio observed in the IVB irons (Fig. 3), therefore, the $\delta^{65} \mathrm{Cu}$ 248 variation is unlikely the result of radioactive decay of nucleosynthetic ${ }^{63} \mathrm{Ni}$.

\subsection{Neutron capture effects on Cu isotopes during GCR-exposure}

250 IVB iron meteorites have large GCR exposure ages of 200-950 Myrs (Voshage and Feldmann, 1979; 251 Herzog, 2007). When exposed to GCR irradiation, secondary neutrons produced by cosmic ray spallation 252 in iron meteorites are captured by siderophile element nuclei. These neutrons are dominantly captured by 253 the most abundant nuclides in iron meteorites, including Fe, Ni, and Co (Leya and Masarik, 2013). 254 Among the Ni isotopes, ${ }^{62} \mathrm{Ni}$ has a thermal neutron capture cross section an order of magnitude larger than 255 for other $\mathrm{Ni}$ isotopes or for $\mathrm{Fe}$ isotopes (Mughabghab, 2003). For ${ }^{62} \mathrm{Ni}$, there is the following reaction:

$$
{ }^{62} \mathrm{Ni}+\mathrm{n} \rightarrow{ }^{63} \mathrm{Ni}\left(\beta^{-}\right) \rightarrow{ }^{63} \mathrm{Cu}
$$

$257{ }^{62} \mathrm{Ni}$ captures a neutron to produce ${ }^{63} \mathrm{Ni}$; since ${ }^{63} \mathrm{Ni}\left(t_{1 / 2}: 100.1 \mathrm{y}\right)$ is unstable, it quickly decays to ${ }^{63} \mathrm{Cu}$. 258 Similarly, for $\mathrm{Cu}$ isotopes (note the branching beta decay):

$$
{ }^{63} \mathrm{Cu}+\mathrm{n} \rightarrow{ }^{64} \mathrm{Cu}\left(\beta^{+}\right) \rightarrow{ }^{64} \mathrm{Ni}(61 \%), \text { or }{ }^{64} \mathrm{Cu}\left(\beta^{-}\right) \rightarrow{ }^{64} \mathrm{Zn}(39 \%)
$$


260 Although both ${ }^{63} \mathrm{Cu}$ and ${ }^{65} \mathrm{Cu}$ can also be burned out by capturing secondary neutrons, the direct effect is 261 negligible compared to the production of cosmogenic ${ }^{63} \mathrm{Cu}$ from ${ }^{62} \mathrm{Ni}$, because ${ }^{63} \mathrm{Cu}$ and ${ }^{65} \mathrm{Cu}$ have smaller 262 neutron capture cross sections (4.5 and 2.2 barns, respectively) than ${ }^{62} \mathrm{Ni}$, and the ${ }^{62} \mathrm{Ni} /{ }^{63} \mathrm{Cu}$ ratio is as high 263 as $5 \times 10^{3}$ in IVB irons. Given the long exposure to GCR, the accumulated ${ }^{63} \mathrm{Cu}$ from ${ }^{62} \mathrm{Ni}$ burn-out leads to 264 a resolvable decrease in ${ }^{65} \mathrm{Cu} /{ }^{63} \mathrm{Cu}$ value in IVB iron meteorites. It should be pointed out that the total 265 burn-out on ${ }^{62} \mathrm{Ni}$ is too small $\left(<0.001 \%\right.$; calculated from $\delta^{65} \mathrm{Cu}$ deviation) to be detected by measuring $\mathrm{Ni}$ 266 isotopic ratios under current analytical precisions ( 0.05\%; Moynier et al. 2007; Regelous et al. 2008), 267 even in the most irradiated sample, Tlacotepec. Similarly, variations in $\delta^{65} \mathrm{Cu}$ are not affected measurably 268 by direct GCR burning of the $\mathrm{Cu}$ isotopes.

269 The deviation of $\delta^{65} \mathrm{Cu}$ from its pre-exposure value depends on the $\mathrm{Ni} / \mathrm{Cu}$ ratio and the dosage of 270 secondary neutrons. The higher the $\mathrm{Ni} / \mathrm{Cu}$ ratio and longer the galactic cosmic ray exposure is, the larger 271 the deviation from the pre-exposure value would be. In IVB iron meteorites, $\delta^{65} \mathrm{Cu}$ values display an 272 apparent positive correlation with $\varepsilon^{189}$ Os and negative correlations with $\varepsilon^{190}$ Os and $\varepsilon^{192} \mathrm{Pt}$ that were 273 measured on a sample taken within $2 \mathrm{~mm}$ from our samples (Fig. 4), with Weaver Mountain and 274 Tlacotepec representing the least and most irradiated samples. This implies that $\delta^{65} \mathrm{Cu}$ of IVB irons was 275 modified by neutron capture effects.

276 The IVB irons contain exceptionally low concentrations of moderately volatile elements (e.g. Ga, Ge, and $277 \mathrm{Cu})$ and high Ni contents $(16-18 \mathrm{wt} . \%)$. The $\mathrm{Cu}$ concentrations of IVB irons measured in this study are 278 1.26-1.77 ppm (Table 2), while most of samples from other groups studied by Bishop et al. (2012) have $279 \mathrm{Cu}$ concentrations higher than $100 \mathrm{ppm}$. The Ni/Cu ratios of IVB group members are generally 100 280 times higher than in other groups of iron meteorites, indicating the deviations of $\delta^{65} \mathrm{Cu}$ induced by GCR 281 irradiation for IVB irons are expected to be 2 orders of magnitude larger than in other iron meteorite 282 groups, given the same cosmic-ray exposure history. For example, given the $\delta^{65} \mathrm{Cu}$ difference $(5.6 \%)$ 283 between the most (Tlacotepec) and the least cosmic ray damaged sample (Weaver Mountains) in IVB 284 group, it is possible to estimate from the $\mathrm{Ni} / \mathrm{Cu}$ ratios that for other iron meteorites with equally long 
exposure-ages as Tlacotepec (945 \pm 55 ma; Voshage and Feldmann, 1979), the $\delta^{65} \mathrm{Cu}$ shift induced by neutron capture effects on ${ }^{62} \mathrm{Ni}$ is expected to be no more than $0.1 \%$, which is barely beyond our current analytical uncertainties. This explains why significantly negative $\delta^{65} \mathrm{Cu}$ only appears in the IVB group and why $\mathrm{Cu}$ isotope variations of other iron meteorite groups (except IVBs) are close to the range defined by chondrites. However, several volatile-depleted ungrouped irons with long exposure ages, e.g., Deep Springs (Scott, 1978; Qin et al. 2008) might also exhibit large $\delta^{65} \mathrm{Cu}$ deviations. Neutron capture reactions will need to be considered for other irons in the future.

\subsection{Pre-exposure $\delta^{65} \mathrm{Cu}$ value derived from correlated $\mathrm{Cu}-\mathrm{Os}-\mathrm{Pt}$ isotope systematics}

The pre-exposure $\delta^{65} \mathrm{Cu}$ can be obtained from the linear correlation between $\mathrm{Cu}$ and $\mathrm{Pt}$, as well as $\mathrm{Os}$ isotopes. As cosmogenic $\varepsilon^{192} \mathrm{Pt}$ anomalies are dependent on $\mathrm{Ir} / \mathrm{Pt}$ ratios, which display a relatively large variation in the IVB group (0.46-1.00 with an average of 0.74; Walker et al., 2008), it is necessary to eliminate the $\varepsilon^{192} \mathrm{Pt}$ bias from chemical differences (Kruijer et al., 2013; Wittig et al., 2013). In $\delta^{65} \mathrm{Cu} v s$. $\varepsilon^{192} \mathrm{Pt}$ space (Fig. $4 \mathrm{c}$ ), all $\varepsilon^{192} \mathrm{Pt}$ values were normalized to a common Ir/Pt value (average value 0.74 ) based on the neutron capture reaction. Like $\varepsilon^{192} \mathrm{Pt}, \delta^{65} \mathrm{Cu}$ deviation induced by GCR also depends on chemical composition ( $\mathrm{Ni} / \mathrm{Cu}$ ratios) and, therefore, should also be normalized to a common $\mathrm{Ni} / \mathrm{Cu}$ value.

But due to the relatively limited $\mathrm{Ni} / \mathrm{Cu}$ variations in IVB irons and possibly larger uncertainties arising from a pre-exposure $\delta^{65} \mathrm{Cu}$ assumption for normalization, $\delta^{65} \mathrm{Cu}$ is not normalized in this study. In contrast, $\varepsilon^{189}$ Os and $\varepsilon^{190}$ Os show anti-correlation (Wittig et al., 2013), with little dependence on the chemical composition, therefore, no normalizations are needed.

In each systematics (Fig. 4), the dashed line is the best-fit regression to the correlation, calculated using Isoplot (Ludwig, 2003). The intercepts to the pre-exposure $\varepsilon^{189} \mathrm{Os}, \varepsilon^{190} \mathrm{Os}$, and $\varepsilon^{192} \mathrm{Pt}$ values (by definition 0) represent the pre-exposure $\delta^{65} \mathrm{Cu}$ value. The $\delta^{65} \mathrm{Cu} v s . \varepsilon^{189} \mathrm{Os}$ (Fig. $4 \mathrm{~A}$ ), $\delta^{65} \mathrm{Cu} v s . \varepsilon^{190} \mathrm{Os}$ (Fig. $4 \mathrm{~B}$ ), and $\delta^{65} \mathrm{Cu} v s . \varepsilon^{192} \mathrm{Pt}$ (Fig. 4C) correlations yield pre-exposure $\delta^{65} \mathrm{Cu}$ values of $-0.3 \pm 1.8$ (95\% conf.), $-0.5 \pm$ 1.2 (95\% conf.), $-0.1 \pm 1.2$ (95\% conf.), respectively. Since the $\varepsilon^{189}$ Os and the $\varepsilon^{190}$ Os both measure the same neutron capture reaction, an error-weighted average of these two yielded $\delta^{65} \mathrm{Cu}$ values of $-0.4 \pm 1.0$ 
(95\% conf.). This value was then averaged with that from Fig. $4 \mathrm{C}$ to obtain $\delta^{65} \mathrm{Cu}$ values of $-0.3 \pm 0.8(95 \%$ conf.). This corrected $\mathrm{Cu}$ isotopic composition for the IVB iron meteorites falls in the range defined by

312 other iron meteorite groups as well as chondrites (Fig. 5). Therefore, our results imply that volatile 313 depletion in IVB meteorites did not fractionate $\mathrm{Cu}$ isotopes by a magnitude greater than that of the range 314 in chondritic $\mathrm{Cu}$ isotope values. Recent measurements of nucleosynthetic anomalies in Ni (Regelous et al., 315 2008), Mo (Burkhardt et al., 2011), Ru (Chen et al., 2010; Fischer-Gödde et al., 2015), Pd (Mayer et al., 316 2015) and W (Qin et al., 2008; Kruijer et al., 2012; Wittig et al., 2013) isotopes show that IVB irons have 317 the largest isotopic anomalies among iron meteorites, similar to the scales observed in chondrites. The 318 IVB irons also show a chondritic pre-exposure $\mathrm{Cu}$ isotope composition within our current analytical 319 precision (Fig. 5).

\section{Conclusions}

322 This study presents $\mathrm{Cu}$ isotopic compositions for 12 of the 14 known IVB iron meteorites. IVB magmatic 323 iron meteorites show significant $\mathrm{Cu}$ isotopic variations $\left(-5.84 \%<\delta^{65} \mathrm{Cu}<-0.24 \%\right.$ ) that resulted from 324 neutron capture on ${ }^{62} \mathrm{Ni}$ induced by cosmic ray exposure. The $\delta^{65} \mathrm{Cu}$ displays clear negative correlations 325 with $\varepsilon^{192} \mathrm{Pt}$ and $\varepsilon^{190} \mathrm{Os}$ and positive correlations with $\varepsilon^{189} \mathrm{Os}$ and $\varepsilon^{182} \mathrm{~W}$, with Weaver Mountains 326 representing the least and Tlacotepec representing the most radiation-damaged samples. The $\delta^{65} \mathrm{Cu}-\varepsilon^{192} \mathrm{Pt}$, $327 \delta \delta^{65} \mathrm{Cu}-\varepsilon^{190} \mathrm{Os}, \delta^{65} \mathrm{Cu}-\varepsilon^{189} \mathrm{Os}$ correlations defined by the IVB irons yield an average pre-exposure $\delta^{65} \mathrm{Cu}$ of $328-0.3 \pm 0.8 \%$ (95\% conf.), which agrees well with the $\mathrm{Cu}$ isotopic compositions of other iron meteorite 329 groups and falls within the range of chondrites. The pre-irradiation $\mathrm{Cu}$ isotope composition of IVB irons $330(-0.3 \pm 0.8 \%)$ provides no support for an evaporative loss of $\mathrm{Cu}$ as the cause of the low $\mathrm{Cu} / \mathrm{Ni}$ ratio of the 331 IVB parental liquid (Campbell and Humayun, 2005). Despite the large uncertainty of the pre-irradiation

$332 \delta^{65} \mathrm{Cu}$ for IVBs, it is clear that the extreme volatile $\mathrm{Cu}$ depletion in IVB irons was not accompanied by 333 enough $\delta^{65} \mathrm{Cu}$ variation to set it apart from other iron meteorite groups. The large neutron capture effect 334 observed in IVB irons is due to the high $\mathrm{Ni} / \mathrm{Cu}$ ratios of these meteorites. Thus, this effect may not be 
335 apparent in most other irons, but may affect some other irons that have undergone significant GCR 336 exposure with lower $\mathrm{Ni} / \mathrm{Cu}$ ratios than IVBs.

\section{Acknowledgements}

339 We thank Julien Foriel for maintaining the clean lab and the MC-ICP-MS facilities at Washington 340 University in St. Louis. We thank the Smithsonian Institution (USNM), American Museum of Natural 341 History (AMNH), Naturhistorisches Museum (Wien), the Monnig Collection at Texas Christian 342 University, Arizona State University, and Harvard Mineralogical Museum are thanked for kindly 343 providing samples. This work was supported by grants from the NASA Cosmochemistry program to 344 Frédéric Moynier (NNX12AH70G) and Munir Humayun (NNX13AI06G).

345 FM thanks the European Research Council for funding under the H2020 framework program/ERC grant 346 agreement \#637503 (Pristine), as well as the financial support of the UnivEarthS Labex program at 347 Sorbonne Paris Cité (ANR-10-LABX-0023 and ANR-11-IDEX-0005-02), the ANR through a chaire 348 d'excellence Sorbonne Paris Cité. 


\section{References}

350

351

352

353

354

355

356

357

358

359

360

361

362

363

364

365

366

367

368

369

370

371

372

373

374

Albarède F. (2004) The stable isotope geochemistry of copper and zinc. in: Johnson, C.M., Beard, B.L., Albarède, F. (Eds.), Geochemistry of Non-Traditional Stable Isotopes, Mineralogical Soc. America, Washington, pp. 409-427.

Archer C., and Vance D. (2004) Mass discrimination correction in multiple-collector plasma source mass spectrometry: an example using $\mathrm{Cu}$ and $\mathrm{Zn}$ isotopes. J. Anal. At. Spectrom. 19, 656-665.

Barrat J.A., Zanda B., Moynier F., Bollinger C., Liorzou C. and Bayon G. (2012) Geochemistry of CI chondrites: Major and trace elements, and $\mathrm{Cu}$ and $\mathrm{Zn}$ Isotopes. Geochim. Cosmochim. Acta 83, 79-92.

Ben Othman, D., Luck J.M., Bodinier J.L., Arndt N.T. and Albarede F. (2006) Cu-Zn isotopic variations in the Earth's mantle (abstract). Geochim. Cosmochim. Acta 70, 46-46.

Bigalke M., Weyer S. and Wilcke W. (2010) Stable Copper Isotopes: A Novel Tool to Trace Copper Behavior in Hydromorphic Soils. Soil Sci. Soc. Am. J. 74, 60-73.

Bigalke M., Weyer S. and Wilcke W. (2011) Stable $\mathrm{Cu}$ isotope fractionation in soils during oxic weathering and podzolization. Geochim. Cosmochim. Acta 75, 3119-3134.

Bishop M.C., Moynier F., Weinstein C., Fraboulet J.G., Wang K. and Foriel J.(2012) The Cu isotopic composition of iron meteorites. Meteorit. Planet. Sci. 47, 268-276.

Braxton D. and Mathur R. (2011) Exploration Applications of Copper Isotopes in the Supergene Environment: A Case Study of the Bayugo Porphyry Copper-Gold Deposit, Southern Philippines. Econ. Geol. 106, 1447-1463.

Burkhardt C., Kleine T., Oberli F., Pack A., Bourdon B. and Wieler R.(2011) Molybdenum isotope anomalies in meteorites: constraints on solar nebula evolution and origin of the Earth. Earth Planet. Sci. Lett. 312, 390-400.

Burkhardt C., Kleine T., Dauphas N. and Wieler R. (2012) Nucleosynthetic tungsten isotope anomalies in acid leachates of the Murchison chondrite: implications for hafnium-tungsten chronometery. Astrophys. J. Lett. 753, 6. 
Campbell A.J. and Humayun M. (2005) Compositions of group IVB iron meteorites and their parent melt. Geochim. Cosmochim. Acta 69, 4733-4744.

Campbell T. J. and Humayun M. (2012) Siderophile element abundances in the Ni-rich ataxites Gebel Kamil, Dumont, and Tinnie. Lunar Planet. Sci. Conf. 43, abstract \#2833.

Chen J.H., Papanastassiou D.A. and Wasserburg G.J. (2010) Ruthenium endemic isotope effects in chondrites and differentiated meteorites. Geochim. Cosmochim. Acta 74, 3851-3862.

Dauphas, N., Marty, B. and Reisberg, L. (2002) Molybdenum evidence for inherited planetary scale isotope heterogeneity of the protosolar nebula. Astrophys. J. 565, 640-644.

Fischer-Gödde M., Burkhardt C., Kruijer T. S. and Kleine T. (2015) Ru isotope heterogeneity in the solar protoplanetary disk. Geochim. Cosmochim. Acta 168, 151-171.

Goldstein J.I., Scott E.R.D. and Chabot N.L. (2009) Iron meteorites: Crystallization, thermal history, parent bodies, and origin. Chemie der Erde - Geochemistry 69, 293-325.

Herzog G.F. (2007) Cosmic-ray exposure ages of meteorites. In: Holland, H. D., Turekian, K. K.(Eds.), Treatise on Geochemistry. Elsevier, Amsterdam, pp.1-36.

Herzog G.F., Moynier F., Albarede F. and Berezhnoy A.A. (2009) Isotopic and elemental abundances of copper and zinc in lunar samples, Zagami, Pele's hairs, and a terrestrial basalt. Geochim. Cosmochim. Acta 73, 5884-5904.

Huang S. and Humayun M. (2008) Osmium isotope anomalies in group IVB irons: cosmogenic or nucleosynthetic contributions (abstract). Lunar Planet Sci. 39, \#1168.

Humayun M. and Clayton R.N. (1995) Potassium isotope cosmochemistry: Genetic implications of volatile element depletion, Geochim. Cosmochim. Acta 59, 2131-2148.

Humayun M. and Cassen P. (2000) Processes determining the volatile abundances of the meteorites and terrestrial planets, In: R. M. Canup and K. Righter (eds.) Origin of the Earth and Moon, University of Arizona Press, Tucson, pp. 3-23.

Humayun M. and Koeberl C. (2004) Potassium isotopic composition of Australian tektites. Meteorit. Planet. Sci. 39, 1509-1516. 
Humayun M. (2012) Chondrule cooling rates inferred from diffusive profiles in metal lumps from the Acfer 097 CR2 chondrite. Meteoritics Planet. Sci. 47, 1191-1208.

Kleine T., Munker C., Mezger K., and Palme H. (2002) Rapid accretion and early core formation on asteroids and the terrestrial planets from Hf-W chronometry. Nature 418, 952-955.

Kleine T., Mezger K., Munker C., Palme H. and Bischoff A. (2004) ${ }^{182} \mathrm{Hf}^{-182} \mathrm{~W}$ isotope systematics of chondrites, eucrites, and martian meteorites: Chronology of core formation and early mantle differentiation in Vesta and Mars. Geochim. Cosmochim. Acta 68, 2935-2946.

Kleine T., Mezger K., Palme H., Scherer E. and Munker C. (2005) Early core formation in asteroids and late accretion of chondrite parent bodies: Evidence from ${ }^{182} \mathrm{Hf}^{-182} \mathrm{~W}$ in CAIs, metal-rich chondrites, and iron meteorites. Geochim. Cosmochim. Acta 69, 5805-5818.

Kruijer T.S., Sprung P., Kleine T., Leya I., Burkhardt C. and Wieler R., (2012) Hf-W chronometry of core formation in planetesimals inferred from weakly irradiated iron meteorites. Geochim. Cosmochim. Acta 99, 287-304

Kruijer T.S., Fischer-Godde M., Kleine T., Sprung P., Leya I. and Wieler R. (2013) Neutron capture on Pt isotopes in iron meteorites and the Hf-W chronology of core formation in planetesimals. Earth Planet. Sci. Lett. 361, 162-172.

Kruijer T. S., Touboul M., Fischer-Gödde M., Bermingham K. R., Walker R. J. and Kleine T. (2014) Protracted core-formation and rapid accretion of protoplanets. Science 344, 1150-1154.

Lee D. C. (2005) Protracted core formation in asteroids: Evidence from high precision W isotopic data. Earth Planet. Sci. Lett. 237, 21-32.

Lee T., Papanastassiou D.A. and Wasserburg, G.J. (1976) Demonstration of ${ }^{26} \mathrm{Mg}$ excess in Allende and evidence for ${ }^{26} \mathrm{Al}$. Geophys. Res. Lett 3, 109-112.

Leya I., Wieler R. and Halliday A.N. (2003) The influence of cosmic-ray production on extinct nuclide systems. Geochim. Cosmochim. Acta 67, 529-541.

Leya I. and Masarik J. (2013) Thermal neutron capture effects in radioactive and stable nuclide systems. Meteoritics Planet. Sci. 48, 665-685. 
Li W., Jackson S.E., Pearson N.J., Alard O. and Chappell B.W. (2009) The Cu isotopic signature of granites from the Lachlan Fold Belt, SE Australia. Chem. Geol. 258, 38-49.

Lodders K. (2003) Solar system abundances and condensation temperatures of the elements. Astrophys. J. $591,1220-1247$.

Luck J.M., Ben Othman D., Barrat J.A. and Albarede F. (2003) Coupled ${ }^{63} \mathrm{Cu}$ and ${ }^{16} \mathrm{O}$ excesses in chondrites. Geochim. Cosmochim. Acta 67, 143-151.

Luck J.M., Othman D.B. and Albarède F. (2005) Zn and Cu isotopic variations in chondrites and iron meteorites: Early solar nebula reservoirs and parent-body processes. Geochim. Cosmochim. Acta $69,5351-5363$.

Ludwig K.R. (2003) Isoplot 3.00: a Geochronological Toolkit for Microsoft Excel. Berkeley Geochronology Center Special Publication vol. 4, p. 70.

Lugmair G.W. and Shukolyukov A. (1998) Early solar system timescales according to ${ }^{53} \mathrm{Mn}-{ }^{53} \mathrm{Cr}$ systematics. Geochim. Cosmochim. Acta 62, 2863-2886.

Marechal C.N., Telouk P. and Albarede F. (1999) Precise analysis of copper and zinc isotopic compositions by plasma-source mass spectrometry. Chem. Geol. 156, 251-273.

Markowski A., Quitte G., Halliday A.N. and Kleine T. (2006a) Tungsten isotopic compositions of iron meteorites: Chronological constraints vs. cosmogenic effects. Earth Planet. Sci. Lett. 242, 1-15.

Markowski A., Leya I., Quitte G., Ammon K., Halliday A.N. and Wieler R. (2006b) Correlated helium-3 and tungsten isotopes in iron meteorites: Quantitative cosmogenic corrections and planetesimal formation times. Earth Planet. Sci. Lett. 250, 104-115.

Masarik J. (1997) Contribution of neutron-capture reactions to observed tungsten isotopic ratios. Earth Planet. Sci. Lett. 152: 181-185.

Mayer B., Wittig N., Humayun M. and Leya I. (2015) Palladium isotopic evidence for nucleosynthetic and cosmogenic isotope anomalies in IVB iron meteorites. Astrophys. Jour. 108, 180 (8 pp).

Moynier F., Albarede F. and Herzog G.F. (2006) Isotopic composition of zinc, copper, and iron in lunar samples. Geochim. Cosmochim. Acta 70, 6103-6117. 
Moynier F., Blichert-Toft J., Telouk P., Luck J.M. and Albarede F. (2007) Comparative stable isotope geochemistry of $\mathrm{Ni}, \mathrm{Cu}, \mathrm{Zn}$, and $\mathrm{Fe}$ in chondrites and iron meteorites. Geochim. Cosmochim. Acta 71, 4365-4379.

Moynier F., Yin QZ, Irisawa K., Boyet M., Jacobsen B. and Rosing M. (2010a) A coupled ${ }^{182} \mathrm{~W}_{-}{ }^{142} \mathrm{Nd}$ constraint for early Earth differentiation. Proc. Natl. Acad. Sci. U.S.A. 107, 10810-10814.

Moynier F., Koeberl C., Beck P., Jourdan F. and Telouk P. (2010b) Isotopic fractionation of Cu in tektites. Geochim. Cosmochim. Acta 74, 799-807.

Mughabghab S.F. (2003) The thermal neutron capture cross sections resonance integrals and G-factors. International Atomic Energy Agency (Internatonal Nuclear Data Commitee), pp. 1-31.

Qin L.P., Dauphas N., Wadhwa M., Masarik J. and Janney P.E. (2008) Rapid accretion and differentiation of iron meteorite parent bodies inferred from ${ }^{182} \mathrm{Hf}^{182} \mathrm{~W}$ chronometry and thermal modeling. Earth Planet. Sci. Lett. 273, 94-104

Rasmussen K.L., Malvin D.J., Buchwald V.F. and Wasson J.T. (1984) Compositional trends and cooling rates of grop-IVB iron meteorites. Geochim. Cosmochim. Acta 48, 805-813.

Regelous M., Elliott T. and Coath C.D. (2008) Nickel isotope heterogeneity in the early Solar System. Earth Planet. Sci. Lett. 272, 330-338.

Righter K., Pando K.M., Danielson L. and Lee C.T. (2010) Partitioning of Mo, P and other siderophile elements $(\mathrm{Cu}, \mathrm{Ga}, \mathrm{Sn}, \mathrm{Ni}, \mathrm{Co}, \mathrm{Cr}, \mathrm{Mn}, \mathrm{V}$, and $\mathrm{W})$ between metal and silicate melt as a function of temperature and silicate melt composition. Earth Planet. Sci. Lett. 291, 1-9.

Savage P., Moynier F., Chen H., Siebert J., Badro J., Puchtel I., and Shofner G. (2015) Copper isotope evidence for large-scale sulphide fractionation during Earth's differentiation. Geochem. Perspect. Lett. 1, 53-64

Schersten A., Elliott T., Hawkesworth C., Russell S. and Masarik J. (2006) Hf-W evidence for rapid differentiation of iron meteorite parent bodies. Earth Planet. Sci. Lett. 241, 530-542.

Schoenberg R., Kamber B. S., Collerson K. D., and Eugster O. (2002) New W-isotope evidence for rapid terrestrial accretion and very early core formation. Geochim. Cosmochim. Acta 66, 3151-3160. 
Scott E.R.D. (1972) Chemical fractionation in iron meteorites and its interpretation. Geochim. Cosmochim. Acta 36, 1205-1236.

Scott E.R.D. (1978) Iron meteorites with low Ga and Ge concentrations-composition, structure and genetic relationships. Geochim. Cosmochim. Acta 42, 1243-1251.

Trinquier, A., Birck, J.L. and Allegre, C.J. (2007) Widespread ${ }^{54} \mathrm{Cr}$ heterogeneity in the inner solar system. Astrophys. J. 655, 1179-1185.

Vockenhuber C., Oberli F., Bichler M., Ahmad I., Quitte G., Meier M., Halliday A.N., Lee D.C., Kutschera W., Steier P., Gehrke R.J. and Helmer R.G. (2004) New half-life measurement of ${ }^{182} \mathrm{Hf}$ : Improved chronometer for the early solar system. Phys. Rev. Lett. 93, 4.

Voshage H. and Feldmann H. (1979) Investigations on cosmic-ray-produced nuclides in iron meteorites, 3. Exposure ages, meteoroid sizes and sample depths determined by mass spectrometric analyses of potassium and rare gases. Earth Planet. Sci. Lett. 45, 293-308.

Voshage H. (1984) Investigations of cosmic-ray-produced nuclides in iron meteorites, 6. The Signer-Nier model and the history of the cosmic radiation. Earth Planet. Sci. Lett. 71, 181-194.

Walker R.J., McDonough W.F., Honesto J., Chabot N.L., McCoy T.J., Ash R.D. and Bellucci J.J. (2008) Modeling fractional crystallization of group IVB iron meteorites. Geochim. Cosmochim. Acta 72, 2198-2216.

Walker R.J. (2012) Evidence for homogeneous distribution of osmium in the protosolar nebula. Earth Planet. Sci. Lett. 351-352, 36-44.

Weinstein C., Moynier F., Wang K., Paniello R., Foriel J., Catalano J. and Pichat S. (2011) Isotopic fractionation of $\mathrm{Cu}$ in plants. Chem. Geol. 286, 266-271.

Williams J.T. and Humayun M. (2013) Origin of the IVB irons in a hit-and-run collision (abstract). Lunar Planet Sci. 44, \#2784.

Wittig N., Humayun M., Brandon A.D., Huang S. and Leya I. (2013) Coupled W-Os-Pt isotope systematics in IVB iron meteorites: In situ neutron dosimetry for W isotope chronology. Earth Planet. Sci. Lett. 361, 152-161. 
505 Yang J.J., Goldstein J.I., Michael J.R., Kotula P.G. and Scott E.R.D. (2010) Thermal history and origin of 506 the IVB iron meteorites and their parent body. Geochim. Cosmochim. Acta 74, 4493-4506.

507 Yin Q.Z., Jacobsen S.B., Yamashita K., Blichert-Toft J., Telouk P. and Albarede F. (2002) A short 508 timescale for terrestrial planet formation from Hf-W chronometry of meteorites. Nature 418, 949$509 \quad 952$ 


\section{Figure Captions}

Fig.1. $\delta^{65} \mathrm{Cu}$ range for the bulk Silicate Earth (BSE), tektites, lunar basalts and soils, chondrites, IVB and other group iron meteorites. The dashed line represents the average $\mathrm{Cu}$ isotopic composition of BSE: $\delta^{65} \mathrm{Cu}=0.07 \pm 0.10 \%$ (2 s.d.; Savage et al., 2015). tektite data are from Moynier et al. (2010b); Lunar soil and basalt data are from Moynier et al. (2006) and Herzog et al. (2009); chondrite data are from Luck et al. (2003) and Barrat et al. (2012); and iron meteorite data are from Bishop et al. (2012). The IVB iron data (before cosmogenic neutron capture corrections) are from this study.

Fig.2. $\delta^{65} \mathrm{Cu}$ versus the degree of crystal-liquid differentiation as represented by the Re concentration for IVB iron meteorites. The external uncertainty is $\pm 0.10(2$ s.d. $)$ for $\delta^{65} \mathrm{Cu}$. Re data are from Walker et al. (2008), except for Dumont which were determined by Campbell and Humayun (2012).

Fig.3. $\delta^{65} \mathrm{Cu}$ versus the Ni/Cu ratio of IVB iron meteorites. The five red dashed lines represent modeled ${ }^{63} \mathrm{Ni}^{-63} \mathrm{Cu}$ evolution diagrams (isochron lines), which assume the initial ${ }^{63} \mathrm{Ni} /{ }^{60} \mathrm{Ni}$ of $1 \times 10^{-5}$ and $\delta^{65} \mathrm{Cu}$ of 0 . The differences in the slopes of the four correlation lines correspond to the differences in times of crystallization.

Fig.4. Correlation of $\delta^{65} \mathrm{Cu}$ (this study) with GCR-modified isotopes (Wittig et al., 2013) (A) $\varepsilon^{189} \mathrm{Os,} \mathrm{(B)}$ $\varepsilon^{190} \mathrm{Os}$, and $(\mathrm{C}) \varepsilon^{192} \mathrm{Pt}$ in IVB iron meteorites. In each panel, the dashed line represents the best-fit linear regression line calculated using Isoplot (Ludwig, 2003) and projection to the x-axis intercept of 0 yields the pre-GCR irradiation $\delta^{65} \mathrm{Cu}$ of the IVB iron meteorite group (black bar, 2 s.d.). Error bars on symbols represent the uncertainties (see Table 2). Uncertainty of $\delta^{65} \mathrm{Cu}$ is $0.10 \%$, which is not resolvable in this figure set due to large span of $\mathrm{Cu}$ variation. 
Fig.5. Comparison of $\mathrm{Cu}$ isotopic composition between primitive meteorites and pre-exposure IVB iron meteorites. The yellow band represents the $\delta^{65} \mathrm{Cu}$ value of Bulk Silicate Earth, i.e. $0.07 \pm 0.10 \%$ o (2 s.d.; Savage et al., 2015). Carbonaceous and ordinary chondrites data are from Luck et al. (2003) and Barrat et al. (2012). 
Table 1. Copper isotopic compositions of USGS geostandards.

\begin{tabular}{cccc}
\hline Geostandard & $\delta{ }^{65} \mathrm{Cu}$ & 2s.d. & Reference \\
\hline BCR-1 & 0.21 & 0.09 & This study \\
& 0.07 & 0.08 & Archer and Vance (2004) \\
\hline \multirow{2}{*}{ BCR-2 } & 0.20 & 0.09 & This study \\
& 0.22 & 0.08 & Bigalke et al., (2010) \\
& 0.18 & 0.08 & Bigalke et al., (2011) \\
\hline BIR-1 & 0.04 & 0.09 & This study \\
& -0.02 & 0.10 & Li et al., (2009) \\
\hline BHVO-2 & 0.13 & 0.09 & This study \\
& 0.10 & 0.07 & Moynier et al., (2010b) \\
\hline AGV-2 & -0.02 & 0.09 & This study \\
& 0.10 & 0.11 & Moynier et al., (2010b) \\
\hline PCC-1 & 0.17 & 0.09 & This study \\
\hline DTS-1 & 0.08 & 0.09 & This study
\end{tabular}


Table 2. $\mathrm{Cu}, \mathrm{W}$, Os, and Pt isotope data of IVB iron meteorites

\begin{tabular}{|c|c|c|c|c|c|c|c|c|c|c|c|c|c|c|}
\hline & $\delta^{65} \mathrm{Cu}^{\mathrm{a}}$ & $n^{\mathrm{b}}$ & $\mathrm{Ni}$ (wt.\%) & $\mathrm{Cu}(\mathrm{ppm})$ & $\mathrm{Ni} / \mathrm{Cu}\left(10^{4}\right)$ & $\operatorname{Re}(p p m)^{c}$ & $\varepsilon^{182} \mathrm{~W}^{\mathrm{d}}$ & $2 \mathrm{se}_{\mathrm{m}}$ & $\varepsilon^{189} \mathrm{Os}^{\mathrm{d}}$ & $2 \mathrm{se}_{\mathrm{m}}^{\mathrm{e}}$ & $\varepsilon^{190} \mathrm{Os}^{\mathrm{d}}$ & $2 \mathrm{se}_{\mathrm{m}}$ & $\varepsilon^{192} \mathrm{Pt}^{\mathrm{d}}$ & 2s.d. ${ }^{\mathrm{f}}$ \\
\hline Cape of Good & & & & & & & & & & & & & & \\
\hline Hope & -2.40 & 2 & 15.68 & 1.30 & 12.0 & 3.06 & -3.6 & 0.18 & -0.32 & 0.11 & 0.11 & 0.06 & 24.6 & 0.8 \\
\hline Dumont & -4.53 & 2 & $16.30^{\mathrm{g}}$ & 1.27 & 12.9 & $2.63^{\mathrm{g}}$ & -3.85 & 0.06 & -0.23 & 0.07 & 0.26 & 0.01 & 23.6 & 0.3 \\
\hline Iquique & -1.96 & 2 & 15.99 & 1.39 & 11.5 & 3.21 & -3.55 & 0.03 & -0.25 & 0.05 & 0.18 & 0.03 & 24.3 & 1.0 \\
\hline Kokomo & -4.30 & 2 & 16.29 & 1.27 & 12.9 & 3.15 & -3.55 & 0.12 & -0.25 & 0.06 & 0.15 & 0.03 & 31.8 & 0.8 \\
\hline Santa Clara & -2.26 & 3 & 17.64 & 1.68 & 10.5 & 1.81 & -3.64 & 0.06 & -0.34 & 0.01 & 0.14 & 0.10 & 13.8 & 0.4 \\
\hline Tinnie & -1.54 & 2 & 17.69 & 1.79 & 9.9 & 1.53 & -3.57 & 0.07 & -0.05 & 0.03 & 0.03 & 0.02 & 6.3 & 0.3 \\
\hline Tlacotepec & -5.84 & 3 & 16.06 & 1.26 & 12.7 & 3.10 & -4.21 & 0.13 & -0.64 & 0.06 & 0.39 & 0.07 & 52.8 & 0.4 \\
\hline Weaver Mountains & -0.24 & 3 & 17.87 & 1.65 & 10.9 & 1.40 & -3.33 & 0.12 & -0.03 & 0.01 & 0.06 & 0.03 & 4.4 & 0.3 \\
\hline Warburton Range & -2.42 & 2 & 17.84 & 1.77 & 10.1 & 1.23 & -3.42 & 0.16 & 0.02 & 0.06 & 0.05 & 0.08 & 5.9 & 0.5 \\
\hline
\end{tabular}

${ }^{a}$ External reproducibilities ( 2 s.d.) are estimated to be $\pm 0.10 \%$ for $\delta^{65} \mathrm{Cu}$

${ }^{\mathrm{b}} \mathrm{n}=$ number of repeat measurements by MC-ICP-MS

${ }^{\mathrm{c}}$ Re data for IVB iron meteorites from Walker et al. (2008)

${ }^{\mathrm{d}} \varepsilon^{182} \mathrm{~W}, \varepsilon^{189} \mathrm{Os}, \varepsilon^{190} \mathrm{Os}$, and $\varepsilon^{192} \mathrm{Pt}$ data from Wittig et al. (2013)

${ }^{\mathrm{e}}$ Uncertainties of $\mathrm{W}$ and $\mathrm{Os}$ isotope data are given as standard error of the mean $\left(2 \mathrm{se}_{\mathrm{m}}\right)$ derived from replicate measurements of the same digestions

${ }^{\mathrm{f}}$ Uncertainties of Pt isotopes are given as in-run standard deviation (2s.d.)

${ }^{\mathrm{g}}$ data from Campbell and Humayun (2012) 


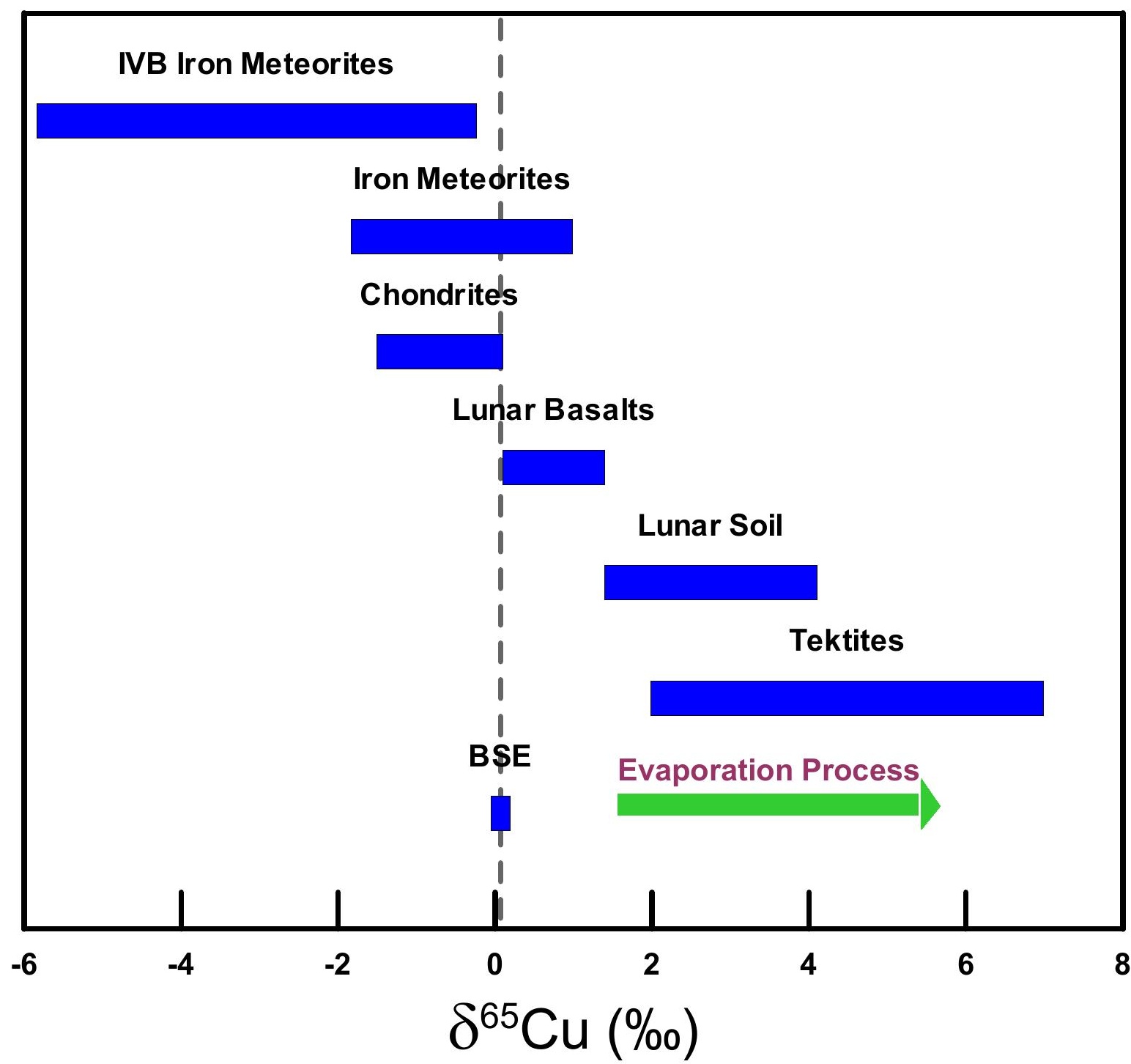


Figure 2

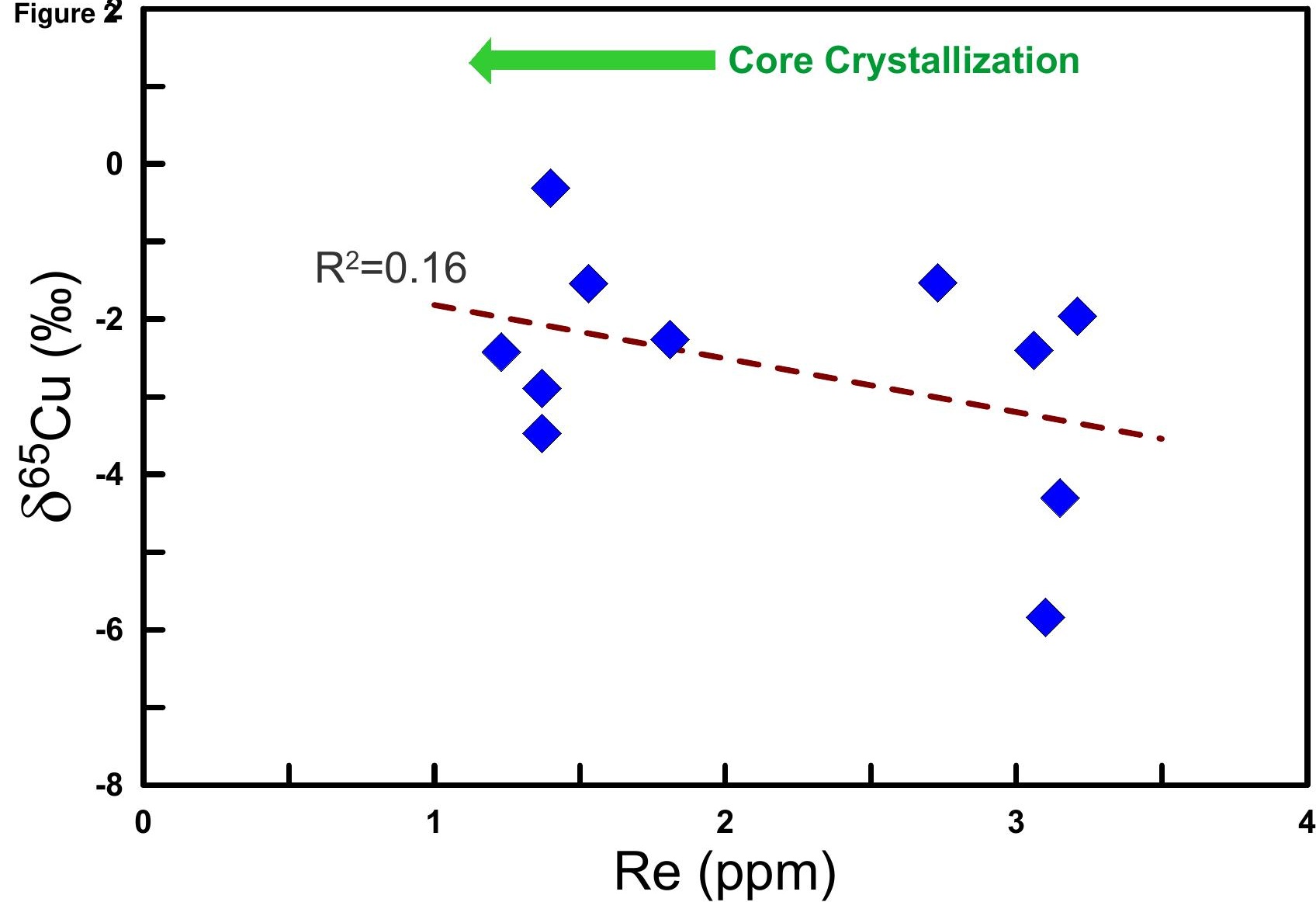

$\operatorname{Re}(p p m)$ 


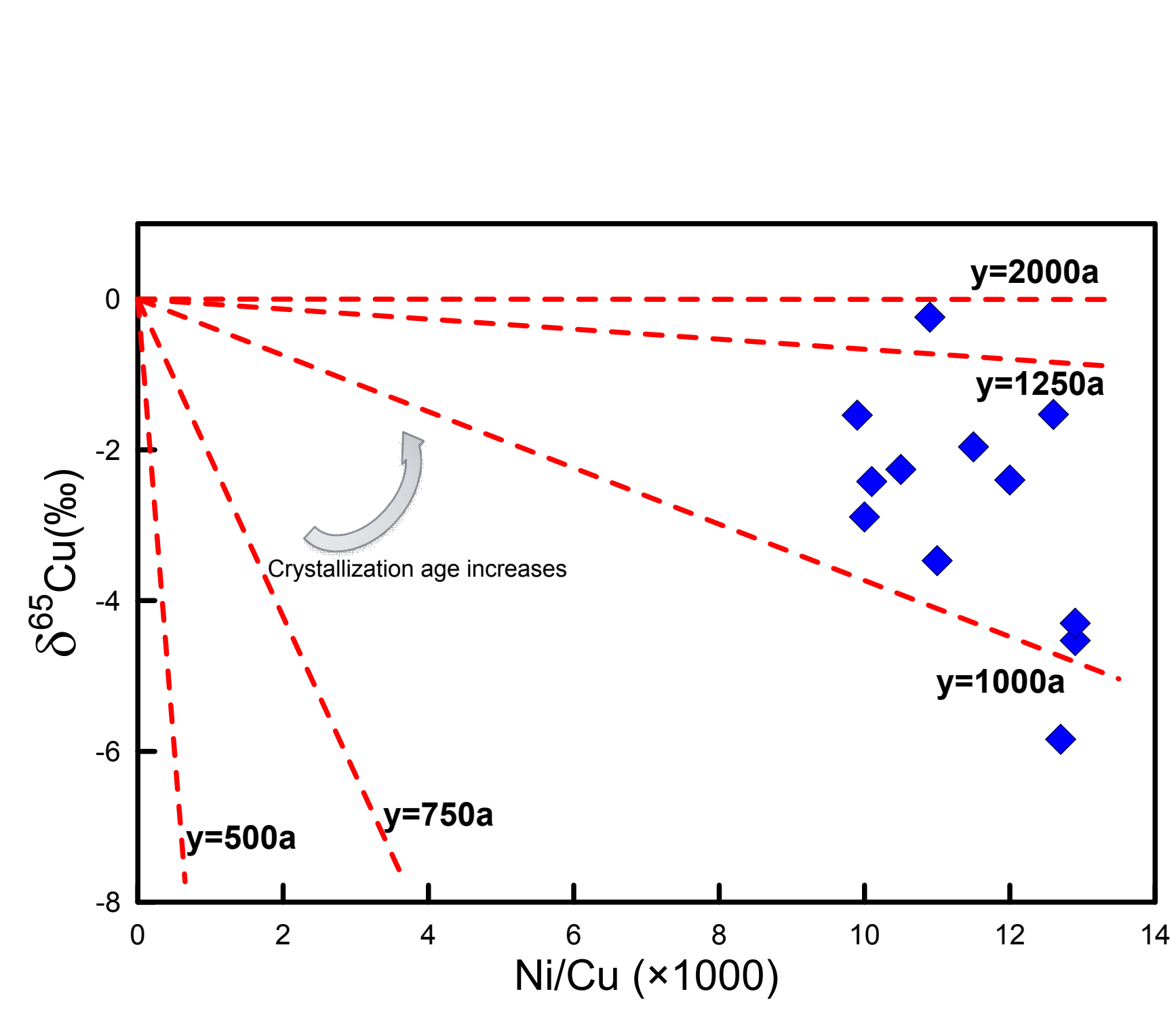

Figure 3

3

4

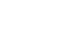

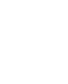

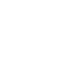
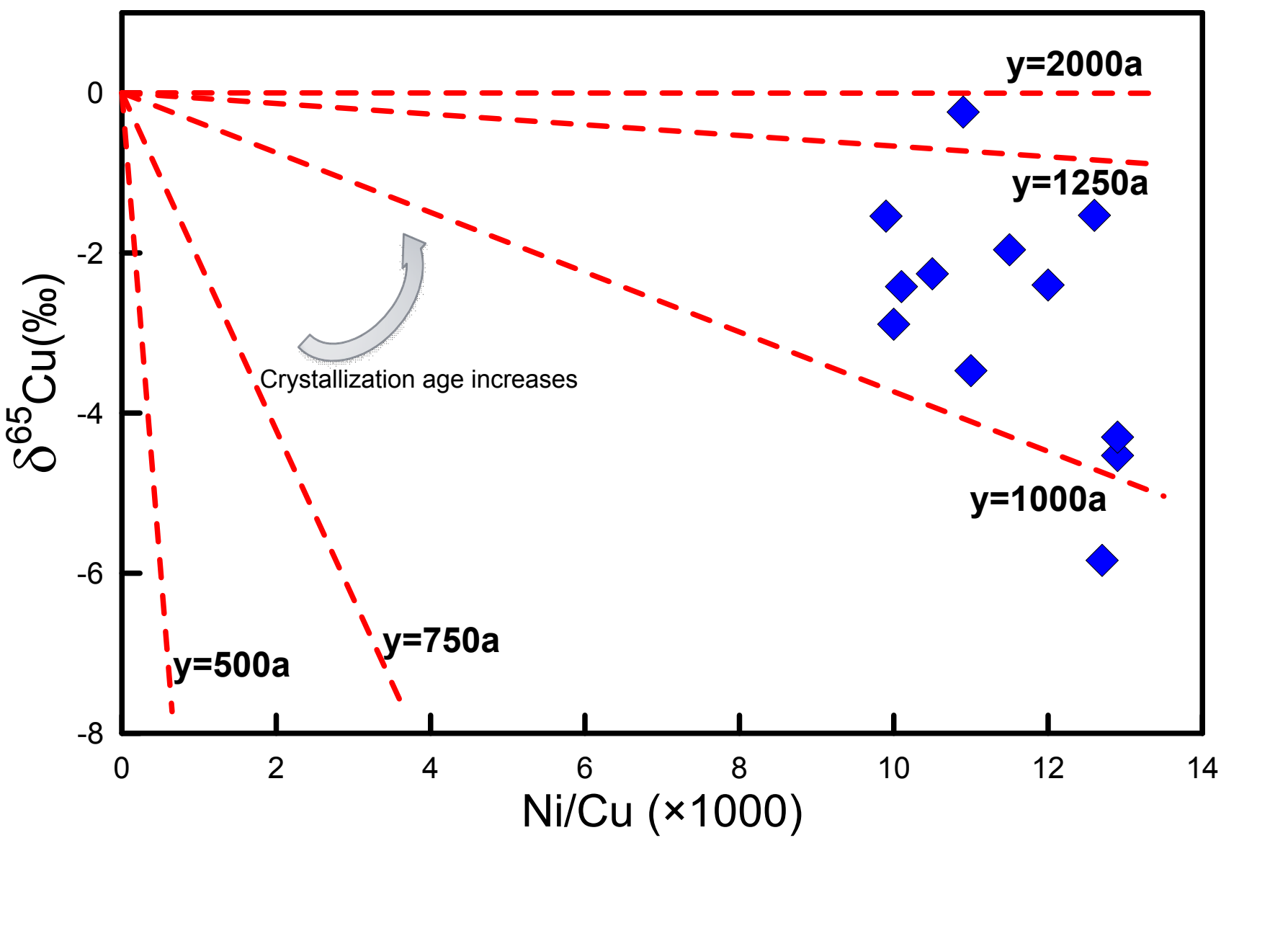

.
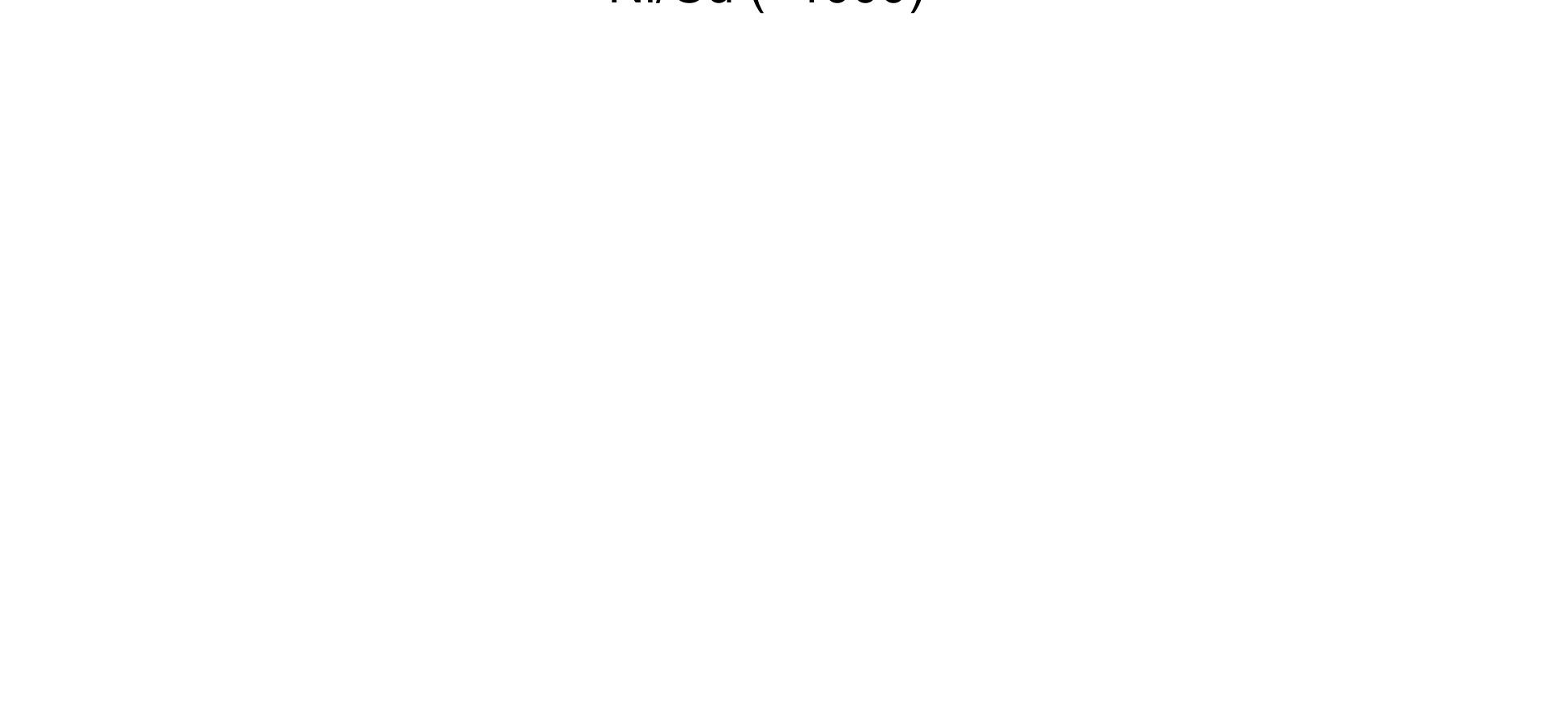

Figure 5

\section{IVB Irons (Pre-Exposure)}

\section{Cl1}

$\mathrm{CO} 3$

CM2

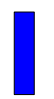

I

CV3

OC

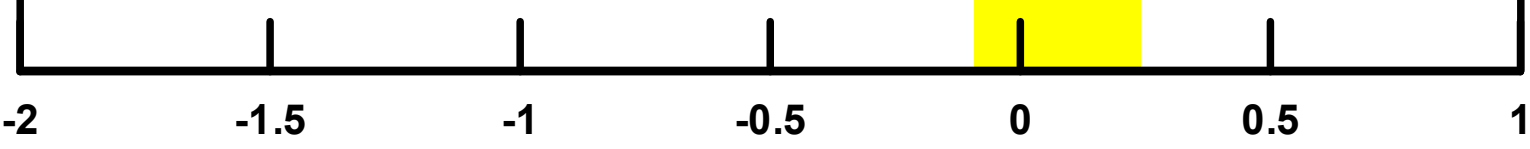

$\delta^{65} \mathrm{Cu}(\% \circ)$ 